\title{
Research on the Fusion Mechanism of Innovation Chain and Fund Chain in Strategic Emerging Industries
}

\author{
Fu Siqi ${ }^{1, a}$, Wang Yudong ${ }^{1, *}$ \\ ${ }^{1}$ School of Economics and Management \\ Harbin University of Science and Technology \\ Harbin, China
}

\begin{abstract}
In order to achieve the fusion of innovation chain and fund chain in strategic emerging industries, improve industrial innovation performance, and realize capital appreciation, based on the connotation and structural characteristics of the two chains, this research analyzes and summarizes the fusion mechanism from three aspects, including the elements, the process of fusion as well as the law of evolution. After research, it is found that the fusion of the innovation chain and fund chain is to integrate on the basis of synergy, then, deepen the synergy and form a spiral system. Lastly, from the point of view of fusion elements, a strategy which can promote the incorporation of the two chains is proposed. This research can be regarded as a reference for the fusion development of the innovation chain and fund chain in strategic emerging industries.
\end{abstract}

\section{INTRODUCTION}

Innovation is the first driving force of development and the strategic support for building a modern economic system. Strategic emerging industries such as new energy, energy conservation and environmental protection, newgeneration information technology, biotechnology and high-end equipment manufacturing, which have huge development potential and play an overall driving and leading role for the economy and society, are the main battlefields for technological innovation. Developing the core and key technologies of strategic emerging industries and improving the efficiency of industrial resources allocation are of great significance to promoting the innovation-driven development of country. Innovation chain is the core chain of the strategic emerging industries. In the meantime, the fund chain plays a supporting role in the stable operation of all links in the strategic emerging industries innovation chain as well as the development of industrial operations. The fusion of the two chains can not only maximize the use of innovative resources and financial resources, but also better improve the innovation performance and realize capital appreciation of strategic emerging industries. Therefore, based on the existing related research materials, this paper explains the fusion mechanism by analyzing the fusion elements of the strategic emerging industries innovation chain and fund chain, the fusion process and the evolutionary law of the fusion, and comes up with some strategies to accelerate the fusion of the two chains from the perspective of the fusion elements, as well as provides a decision-making reference for the fusion development of the strategic emerging industries innovation chain and fund chain.

\section{LITERATURE REVIEW}

The research on the relationship between innovation chain and fund chain mainly contains the constraint of the government support for innovation, financing restriction on innovation, the impact of $R \& D$ investment and financing methods on innovation, the promotion of capital allocation related to the innovation chain, as well as the impact of different stages and capital investment on innovation performance. In terms of the government support for innovation, Selvarajah K et al. (2017) put forward that innovation level should be improved through strengthening governance mechanism, Wu Jian et al. (2018) found that government subsidies can play the role of resource attributes, promote innovation input of strategic emerging industries, and boost innovation output [2]. In terms of the inhibitory action of financing restrictions on innovation, Hottenrott $\mathrm{H}$ and Peters $\mathrm{B}$ (2012) have concluded that financing constraints are not dependent on the availability of internal funds, but are driven by the ability to innovate [3], Li Yuanyuan (2020) concluded that financing constraints are significantly negatively correlated with innovation efficiency in strategic emerging industries [4]. As for the impact of $R \& D$ investment and financing methods on innovation, as reported in the study conducted by Li Weizhong (2020) et al., it is said that building up a sustainable growth mechanism of research and development investment has a significant effect on improving technological innovation performance [5], from the perspective of research and 
development as well as cooperation methods, Wu Jun and Huang Dongmei (2016) came up with policy suggestions of innovation efficiency related to products and process in strategic emerging industries [6]. When it comes to the promotion of capital allocation of the innovation chain, Zheng Wenfan (2019) found that the allocation of capital chains that focuses on the innovation chain helps to promote scientific and technological innovation activities [7], which is conducive to cracking down upon the "islanding phenomenon" in scientific and technological innovation and improving the efficiency of technological innovation [8]. Zhang Huiying and Dai Wanliang (2011) constructed a model of innovation capital chain, and believed that the entire innovation capital is essentially a cyclical process in which capital supports technological innovation [9]. In terms of the impact of different stages and capital investment on innovation performance, $\mathrm{Li}$ Peinan (2014) divided the innovation stage into two stages: technology development and achievements conversion, and studied the influence of different stages on innovation performance [10]. Also, Yang $\mathrm{Wu}$ and Yang Dafei (2019) found that the current personnel investment is in a good state, and excessive emphasis on capital investment will inhibit the improvement of innovation performance [11].

To sum up, the current research on the relationship between the innovation chain and the fund chain mainly includes the government support for innovation, the restraint of financing restrictions on innovation, the impact of $R \& D$ investment, financing methods, the allocation of funds which focuses on the innovation chain, as well as the impact of different stages and capital investment on innovation performance. And the research on multi-chain fusion mainly focuses on the macro study of the development strategy on multi-chain fusion and the support of financial system of the multi-chain fusion [12], as well as the "four-chain" fusion rule based on domestic and foreign practices [13]. However, there are few literatures related to the fusion mechanism of innovation chain and fund chain and the effect of fusion on innovation performance. From a systematic point of view and according to the structure and characteristics of the innovation chain and fund chain in strategic emerging industries, this article analyzes the fusion mechanism of innovation chain and fund chain from three aspects which includes the fusion elements, the fusion process and the law of evolution, and comes up with some strategies to promote the fusion of dual chains from the perspective of fusion elements. Improve the efficiency of industrial resources allocation and innovation performance through the fusion of the two chains.

\section{ConNOtATION AND ElEMENT ANALYSIS ON THE CONCEPT AND FUSION OF INNOVATION Chain and Fund Chain In Strategic EMERGING INDUSTRIES}

\subsection{The Connotation of Innovation Chain and Fund Chain}

- Connotation of the innovation chain. Kang Jian and $\mathrm{Hu}$ Zuguang (2017) concluded that the innovation chain is based on the value association of the main bodies in the industry chain. According to the function of each main part, it can be classified into nodes and supporting points. The nodes include upstream and downstream enterprises, scientific research institutes and colleges and universities. The supporting points include intermediary agencies, governments, banks, etc. [14]. Sen (2003) believes that the innovation chain is a complete chain which includes the generation of innovative thinking, the conversion of research fruits and the realization of creative products [15]. In this paper, the connotation of the innovation chain of strategic emerging industries is defined as: take the strategic emerging industries as the core subject, take the market demand as the guide, connect the relevant innovation participants and innovation links through creative activities, so as to meet the market demand and realize the circular chain structure of the industrialization of innovation fruits, it includes research and development stage, achievement transformation stage, marketization stage and industrialization stage. Each node of the innovation chain is closely related to each other, and the completion of the previous innovation section will facilitate the progress of the next link [16]. In addition, the innovation chain is mainly composed of strategic emerging industries, and cooperative innovation can also be carried out by governments, universities and scientific research institutions during the process of research and development.

- Connotation of the fund chain. From the perspective of innovation, the fund chain is formed by different forms of financial support in the process from research and development to industrialization [17]. From the perspective of enterprises, the fund chain is a chain of capital supply and demand formed in the process of value creation between enterprises and among all links within enterprises [18]. In this paper, the connotation of the fund chain of strategic emerging industries is defined as: To support the development of industrial operation, to meet the demand for capital in each link of innovation chain, so as to promote the industrialization chain of innovation results. The fund chain includes three stages: the first stage is the funding of the industrial capital, that is the source of money, the 
second phase is the use of funds, which means the investment into the industrial innovation research and development as well as production and operation, the third stage is the return and reallocation of capital, that is, the reinvestment of innovation after capital appreciation.

\subsection{Connotation of Fusion of Innovation Chain and Fund Chain}

Li Xiaofeng (2018) believes that the essence of the "four chains" is the deepened cooperation and in-depth synergy of different innovation entities [19]. This paper defines the concept of the fusion of innovation chain and fund chain as a dynamic fusion process that deepens collaboration between the strategic emerging industries innovation chain and fund chain, which improves industrial innovation performance and capital value-added capabilities, and meanwhile, the system presents a spiral trend. The fusion of innovation chain and fund chain can optimize the allocation of innovation resource elements, reduce the uncertainty and risk in the process of innovation activities, as well as improve the innovation performance.

\subsection{Analysis of The Fusion Elements of Innovation Chain and Fund Chain}

There are three main aspects for the fusion elements on innovation chain and fund chain. The first one is the driving force of the fusion, the second one is the ability to fusion, and the last one is the opportunity for the fusion.

- The driving force of the Fusion of innovation chain and fund chain. The driving force of fusion is the basic condition to realize the fusion of the strategic emerging industries innovation chain and fund chain. If there is no driving force of the fusion, then fusion activities will not occur. The driving force of fusion refers to the combination of all the conditions and factors that generate the demand for double-chain fusion under the combined effect of various factors in the strategic emerging industries innovation chain and fund chain. Therefore, being driven by various factors is a prerequisite for the fusion. The driving factors of the fusion power are mainly reflected in two aspects: one is that the ultimate goal of the strategic emerging industries is to pursue innovation and profit maximization; the other one is that government investment can encourage the industry to make more efforts in innovation.

- The ability of the fusion of innovation chain and fund chain. The ability to fusion is an important guarantee for the realization of double-chain fusion. The specific factors are reflected in the following: the richer the technological and talents accumulation of the strategic emerging industries is, the more technical support it can provide for innovative activities; the stronger the financing ability is, the more strength the financial support for innovation activities will have; the better the capital operation ability is and the lower the cost is, the stronger the support for innovation chain will be; the stronger the development capacity is, the greater the potential for its expansion and strength will be.

- Opportunity for the fusion of innovation chain and fund chain. The opportunity of fusion refers to the situation that is conducive to the realization of innovation goals in the innovative activities of the strategic emerging industries. The specific factor can be regarded as the preferential tax policies. Mastering the preferential tax policies is equivalent to broadening the financing channels to a certain extent, further promote the fusion of the two chains.

\section{ANALYSIS ON THE PROCESS AND EVOLUTIONARY LAW OF THE FUSION OF INNOVATION CHAIN AND FUND CHAIN IN STRATEGIC EMERGING INDUSTRIES}

\subsection{The Fusion Process of Innovation Chain and Fund Chain}

The double-chain fusion of the strategic emerging industries is carried out on the basis of synergy, so the relationship between each link will be deeper than synergy. First of all, from research and development to final industrialization link, it is necessary to strengthen the information feedback and adjustment capabilities on the basis of manpower, capital, and information sharing. Additional personnel can be added to the financial department to carry out special management, so as to accurately allocate manpower and capital as well as provide related information feedback timely. The research and development stage may face the risk of failure. Therefore, it is more difficult to obtain funds from a bank. It is necessary to well arrange its own funds and government investment according to the total capital. In the stage of achievement transformation, funds are also needed to support the research and development results from applied research to production. At this stage, due to the product has been created, and the uncertainty is reduced, the possibility of obtaining bank loans will increase, while it is still necessary to timely and rationally arrange the type, scale and quantity of capital investment according to shared information and the total capital. With the expansion of production scale and mortgageable assets increase, which can be met by loans from financial and non-financial institutions [20], at this time, the innovation risk is reduced but faces the risk of marketization failure, venture capital has become an important form of combination with innovation chain, funding the innovation chain. At the industrialization stage, the production and sales of products have developed on a large scale, banks and other financial institutions are willing to provide loans [21], in this stage, innovation performance has been significantly improved and the 
funds has been fully appreciated. Figure 1 shows the fusion process of the strategic emerging industries innovation chain and fund chain.

The innovation chain and the fund chain have the function of efficiently integrating the innovation elements of each link of innovation, realizing the optimal allocation of resources through the fusion, and ultimately achieving the improvement of innovation performance. However, the degree of double-chain fusion is influenced by three aspects: the driving force of the fusion, the ability of the fusion, and the opportunity for the fusion, as a result, the improvement of innovation performance can be seen as driven by these three factors. Figure 1 shows the fusion process of the strategic emerging industries innovation chain and fund chain.

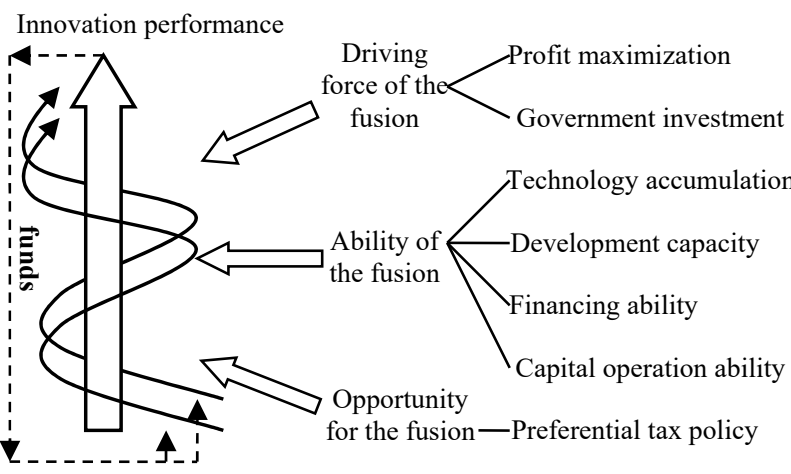

Figure 1. Process of fusion of innovation chain and fund chain in strategic emerging industries

It can be seen from Figure 1 that the elements of the fusion of strategic emerging industries innovation chain and fund chain all promote the fusion of the two chains, thereby improving innovation performance and capital appreciation, and then the value-added capital can be invested in the key links of the innovation chain and fund chain to ensure the stable operation of innovation chain and fund chain, thus the whole system realizes a virtuous circle.

\subsection{The Evolutionary law of the Fusion of Innovation Chain and Fund Chain}

As the connected of innovation chain and fund chain has become more and more closely, the relationship between the two chains have also changed. Initially, the resource elements in the two chains have complementary effects in terms of scale, time and function, and they have reached a matching state; then the innovation chain and fund chain penetrate and promote each other, and the two chains generate a synergistic effect which is greater than the mere sum of each parts. Finally, the innovation chain and fund chain continue to deepen the synergy, forming a spiral system. Figure 2 shows the evolution process of the fusion of the strategic emerging industries innovation chain and fund chain.

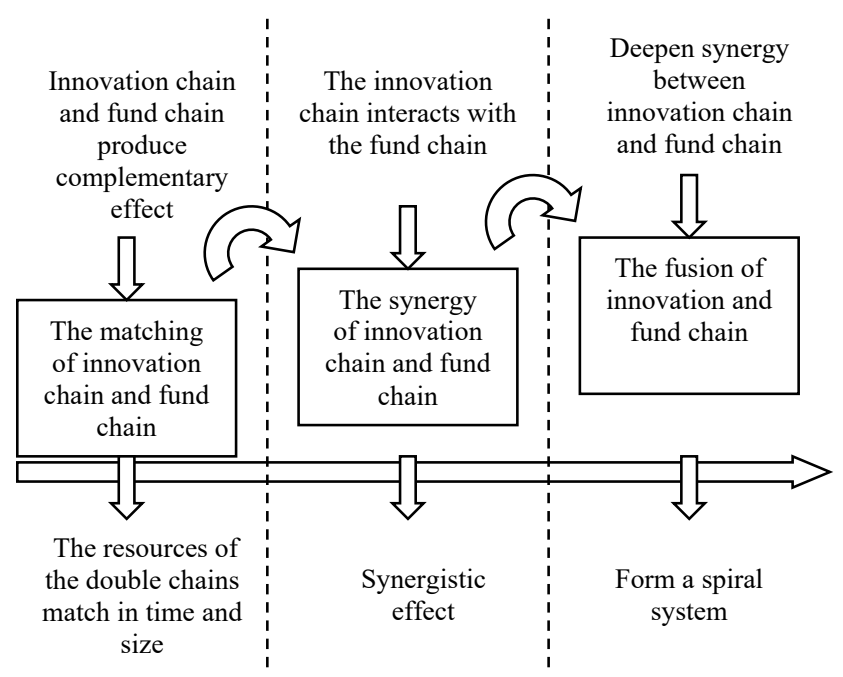

Figure 2. Evolutionary Law of Fusion of strategic emerging industries Innovation Chain and Fund Chain

In the matching stage of innovation chain and fund chain, each node in the innovation chain has different requirements for capital in terms of time and scale of demand, and it is necessary to allocate capital according to the structural characteristics of the innovation chain, the allocation of funds at each node in the innovation chain is interconnected and restricted. The lack or redundancy of funds at any node in the innovation chain will directly affect innovation capabilities and performance.

In the stage of synergy between the innovation chain and fund chain, the functions of the two chains are different, and can effectively optimize the allocation of innovative resources and elements such as talents, capital, information, and technology. The innovation elements and capital elements will transform from disorder to an organized state, hence the transformation produces a synergistic effect that one plus one is greater than two, which in turn strengthens innovation-driven development momentum, improves the sustainability of innovation, and then promotes the industry development.

In the fusion stage of innovation chain and fund chain, the two chains deepen their roles and form a spiral system. The relationship between the two chains tends to be integrated. Under the fusion state, the allocation of resources in all stages of innovation activities can be carried out stably and efficiently. The chain can provide innovative resources and financial resources in both directions in a timely manner at each node, thereby achieving stable improvement in innovation performance.

\section{Conclusions AND ReCOMmENDATIONS}

\subsection{Conclusions}

At present, strategic emerging industries are still in the development stage, rational allocation of innovation resources and capital resources is conducive to the stable development of the industry. After research, this paper concluded that the fusion of the strategic emerging 
industries innovation chain and fund chain can improve innovation performance while improve the efficiency of resource allocation. In essence, the substance of doublestrand fusion is the process of synergy deepening. The realization of fusion requires the three elements of power, ability, and conditions. Moreover, more power, stronger abilities, and the more advantageous conditions will bring the better effect of the fusion and the innovation performance. Through the process of fusion and the evolutionary law of the two chains fusion of the strategic emerging industries, it can be known that the fusion of innovation chain and fund chain can develop in a spiraling state, and continuously promote the enhancement of innovation performance, and vice versa, which means they will return to enrich innovation and capital resources, as well as promote each other, forming a virtuous circle and promote the development of strategic emerging industries.

\subsection{Recommendations}

The government should give more subsidies to some strategic emerging industries with slow development, and establish oriented subsidy system and effectively supervise the subsidies to ensure the balanced development of strategic emerging industries. According to the total amount of funds for rational configuration and the focus should be to maximize the utility of funds as the goal. During the stage of innovation knowledge output and achievement, a large amount of capital and research and development personnel investment is required, at the stage of industrialization, the investment of research and development resources should only be supplemented on the basis of the previous stage and appropriately reduced, and more attention should be paid to the investment in commercial operation resources. Innovation activities themselves have greater risks and uncertainties, which are likely to cause financing difficulties, and tax incentives can be used as a financing channel. Making good use of this point is conducive to avoiding the strategic emerging industries from getting into financing troubles.

\section{ACKNOWLEDGMENT}

This research was supposed by the National Natural Science Youth Foundation of China (71601059), the Ministry of Education of Humanities and Social Science project (19YJA790087).

\section{REFERENCES}

1. Selvarajah. K,Sheena. S. S. P.Innovation Investment:An Empirical Study of Technology Public Listed Companies in Malaysia[J].American Journal of Economics,2017,7(1):15-24.

2. Wu Jian, Tian Zhilong, Long Xiaofeng, Xiong Qi. The Influence of Government Subsidies on Enterprise Innovation in Strategic Emerging
Industries[J]. Studies in Science of Science, 2015,36(01):158-166.

3. Hottenrott. H,Peters. B. Innovative Capability and Financing Constraints for Innovation: More Money, More Innovation?[J]. Review of Economics \& Statistics, 2012, 94(4):1126-1142.

4. Li Yuanyuan. Financing Constraints, Risk Bearing and Innovation Efficiency of Enterprises in Strategic Emerging Industries[J]. Pioneering With Science \& Technology Monthly, 2020,33(08):50-53.

5. Li Weizhong, Chen Haiquan, Li Xingxing, Ren Zhikuan. Research on the Influence of Knowledge Acquisition and R\&D Fund on Technological Innovation Performance-Discussing The Moderating Effect of Ownership Nature and Internal Governance Structure[J]. Science and Technology Management Research,2020,40(13):226-233.

6. Wu Jun, Huang Dongmei. Research and Development Subsidies, Industry-university-research Cooperation and Innovation in Strategic Emerging Industries[J]. Scientific Research Management,2016,37(09):20-27.

7. Zheng Wenfan, Liu Mingwei. Research on R\&D Investment Fund Chain Concentrated on Innovation Chain[J]. Journal of Northeastern University (social science), 2019,21 (06) : 559-566.

8. Chen Yuling. Solving the "Isolated Island Phenomenon" in Scientific and Technological Innovation[J]. People's Tribune,2019(03):78-79.

9. Zhang Huiying, Dai Wanliang. The Conceptual model of Regional Innovation Value Chain Based on Innovation Value Chain[J]. Science\&Technology Progress and Policy, 2011,28(01):28-32.

10. Li Peinan, Zhao Lanxiang, Wan Jinbo. The Influence of Innovation Factors on Industrial Innovation Performance_An Empirical Analysis based on China's Manufacturing and High-tech Industry Data[J]. Studies in Science of Science,2014,32(04):604-612.

11. Yang wu, Yang Dafei, Lei Jiasu. The influence of R\&D investment on Technology Innovation Performance Study[J]. Studies in Science of Science, 2019,37(09):1712-1720.

12. Zhang Ling, Zhang Sheng. Financial Support System for Innovation-driven Development Strategy[J]. Journal of Xi'an Jiaotong University,2015,35(6):2429.

13. Li Xiaofeng, Li Chuncheng. Law and Enlightenment of Regional Four-chain Fusion based on Practices at home and abroad[J]. Science Technology and Industry,2016,16(09):1-4.

14. Kang Jian, $\mathrm{Hu}$ Zuguang. Research on the Relationship Between Multiple Networks within The Innovation Chain, Entrepreneurial Ability and Entrepreneurial Performance[J]. Science and Technology Management Research,2017,37(02):716. 
15. Sen.Innovation chain and CSIR[J].Current Science, 2003,85(5):570-574.

16. Liu Jiashu, Fan Conglai, Qi Xin. Research on the Heterogeneous Effect of Financial Support Embedded Innovation Chain[J]. Jiangsu Social Sciences,2016(05):1-8.

17. Yuan Jixin, Wang Xiaoyong, Lin Zhijian, Ye Jing. An Empirical Study on the "Three-chain Integration" of Industrial Chain, Innovation Chain and Capital Chain_-A Case Study of zhejiang Intelligent Health Industry[J]. Science and Technology Management Research,2016,36(14):31-36+44.

18. Zhang Jinchang, Fan Ruizhen, Hu Tianyu. Research on the Measurement Method of Enterprise Capital Chain Fracture Risk[J]. Business Management Journal,2015,37(1):190-199.
19. Li Xiaofeng. Theoretical Research on "Four Chains" Fusion to Enhance the Energy level of Innovative System[J]. Scientific Research Management, 2008,39(09):113-120.

20. Md. Q., Wei J..Nexus Between Financial Innovation and Economic Growth in South Asia:Evidence from ARDL and Nonlinear ARDL Approaches[J]. Financial Innovation, 2018(1):2021.

21. Huang Y., Swamidass. P., Raju. D. A.. The Nature of Innovation in Emerging Industries in China:An Exploratory Study $[\mathrm{J}]$. The Journal of Technology Transfer,2016(3):451-468. 